\title{
Modified Release Dosage Form
}

National Cancer Institute

\section{Source}

National Cancer Institute. Modified Release Dosage Form. NCI Thesaurus. Code C42712.

A solid, semi-solid, solution or suspension exhibiting an altered inherent rate of release of active and/or inert ingredient(s). 